\title{
Delayed cephalic arch rupture following balloon angioplasty
}

\author{
Abdulaziz Algharras* (D)
}

\begin{abstract}
Background: Vascular access care comes with its substantial cost that include but not limited to poor blood flow during dialysis, stenosis throughout the dialysis circuits, aneurysmal dilatation, clots formation and complete thrombosis. Acute cephalic arch rupture is not that uncommon but delayed rupture is rare presentation that was not discussed previously.

Case presentation: We describe a case of a 70-year-old female with end-stage renal disease (ESRD) undergoing a fistulogram and angioplasty of cephalic arch stenosis that resulted in a small vessel rupture that was successfully treated with prolonged balloon inflation initially. Unfortunately, this was complicated with massive venous rupture after initiating hemodialysis. The diseased segment was successfully treated with covered stent placement. This paper review and discuss cephalic arch stenosis, clinical presentation, and available initial and bailout treatment strategies.

Conclusions: Primary management of cephalic arch rupture is a prolong-low pressure balloon angioplasty, with covered stent across the site of extravasation if persisted. This case depicted a delayed vascular rupture following hemodialysis in patient with previously controlled extravasation that necessities covered stent placement. No data in the literature suggested the time that is required to avoid dialysis and improve healing.
\end{abstract}

Keywords: Cephalic arch, Angioplasty, Extravasation, Venous rupture, Vessel rupture

\section{Background}

Kidney transplantation is the ideal scenario in management of patient with end stage renal disease (ESRD), however hemodialysis and peritoneal dialysis are interim strategy while waiting for transplantation. In term of fistula creation, radiocephalic fistula is the favored primary site followed by brachiocephalic fistula [1]. Vascular access care comes with its substantial cost that include but not limited to poor blood flow during dialysis, stenosis throughout the dialysis circuits, aneurysmal dilatation, clots formation and complete thrombosis. Cephalic vein stenosis is one of those challenges that can be seen on doppler ultrasound study or fistulogram.

Acute cephalic arch rupture is not that uncommon but delayed rupture is rare presentation that was not

\footnotetext{
*Correspondence: algharras@gmail.com

Department of Radiology, Unaizah College of Medicine and Medical

Sciences, Qassim University, Buraydah, Saudi Arabia
}

discussed previously. We describe a case of a 70-year-old female with ESRD undergoing a fistulogram and angioplasty of cephalic arch stenosis that resulted in a small vessel rupture that was successfully treated with prolonged balloon inflation initially. Unfortunately, this was complicated with massive venous rupture after initiating hemodialysis. The diseased segment was successfully treated with covered stent placement. This paper review and discuss cephalic arch stenosis, clinical presentation, and available initial and bailout treatment strategies.

\section{Case presentation}

A 70-year-old female on hemodialysis via left brachiocephalic fistula created four years back. The patient had thrombosed and dysfunctional fistula, which was treated with mechanical thrombectomy and balloon angioplasty of the cephalic vein in an outside health care center. The fistula was complicated by minor extravasation at the 
cephalic arch, which was well managed with balloon tamponade.

In the following day, she returned to the dialysis center and underwent a hemodialysis session at the same access site. Shortly after the dialysis, she started to developed chest wall pain and swelling. Patient transferred to the emergency department; urgent complete blood count depicted a marked drop in the hemoglobin level $7 \mathrm{gm} /$ $\mathrm{dl}$ (baseline $10 \mathrm{gm} / \mathrm{dl}$ ). The cephalic vein was completely thrombosed with a patent brachial artery on ultrasound. Then, a fistulogram was done right away.

A venous $5 \mathrm{~F}$ sheath (Terumo Medical, Japan) was initially inserted, and a fistulogram revealed long segment thrombosis of the cephalic vein. massive contrast extravasation at the level of previously treated segment with multiple clots proximally was seen after contrast injection close to the arch (Fig. 1). Many attempts to cross the rupture from the same access were unsuccessful. As a result, a through-and-through access was achieved using a femoral access, an angled tip catheter, and wire access to the cephalic vein, which was snared using a snare kit device (Argon Medical, USA).

An attempt for a prolonged low-pressure balloon angioplasty using $8 \mathrm{~mm}$ balloon (Armada, Abbott, USA) that was inflated to burst pressure for 2 min then 5 min were not successful, therefore a decision was made to place two $8 \mathrm{~mm} \times 8 \mathrm{~cm}$ covered stent (Viabahn, Gore Medical, USA) to seal the perforation site as the first stent did not seal the perforation completely. No attempt was done for declotting as the patient condition was not permissible, however a temporary tunneled dialysis catheter (Bard Medical, USA) via right jugular access. She was placed on aspirin; however, since the patient had just recovered

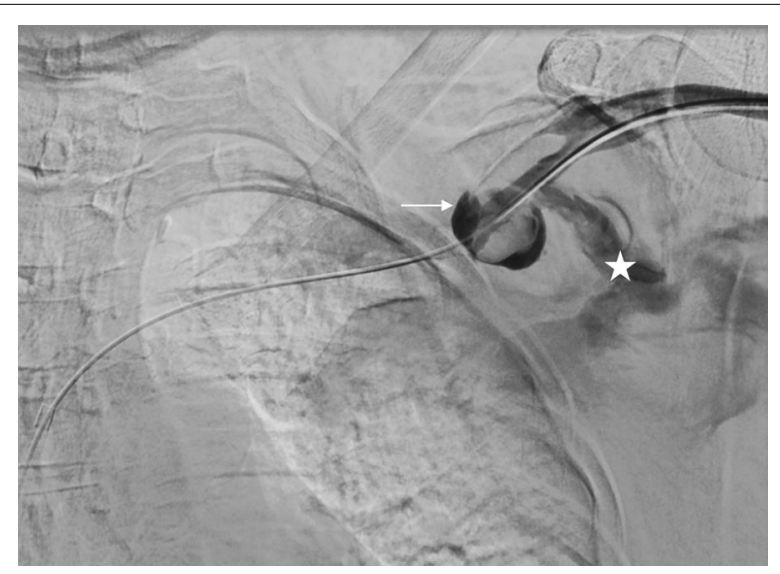

Fig. 1 Fistulogram shows contrast extravasation in the chest wall (star) associated with thrombosis of the cephalic vein proximally as well as partially thrombosed aneurysm centrally (white arrow) from a major bleeding attack, adding another anticoagulant was not an option.

After the patient has been stabilized, and one-week later, fistulogram showed intact cephalic arch with complete resolution spontaneously of previously seen clots throughout the fistula (Fig. 2).

\section{Discussion}

Cephalic vein stenosis is a well-known outcome for dysfunctional brachiocephalic arteriovenous fistulas particularly in the most central portion 1mainly due to mechanical stresses that can result in intimal and medial hyperplasia [2, 3]. Distinctive signs for outflow stenosis consist of slow flow rate, prolonged bleeding and access thrombosis and clots [4]. Standard treatment for such is balloon angioplasty with lower patency rate of $23 \%$ at 1 year, and its major complication is vessel rupture at rate of $0.5 \%$ [4]. Other possible treatments include covered stent graft placement and surgical transposition of the cephalic vein [5].

It is noted that the rate for venous rupture reach up to $15 \%$ at the level of the cephalic arch in comparison to less than $3 \%$ in the other sites in the dialysis circuits $[6,7]$. Such complication usually treated with prolonged low pressure balloon inflation (3-5 min, with no data to support specific timing) that can be repeated couple times, if persisted, covered stent placement is the choice during the same session [8-10]. If there is difficulty in crossing the extravasation, vein ligation or coil embolization may be required to control the bleeding $[10,11]$.

There is no data on post angioplasty management for those patients. There are two options that may arise. One, if the patient treated with covered stent, then resuming dialysis immediately has no issue. Two, if the patient is

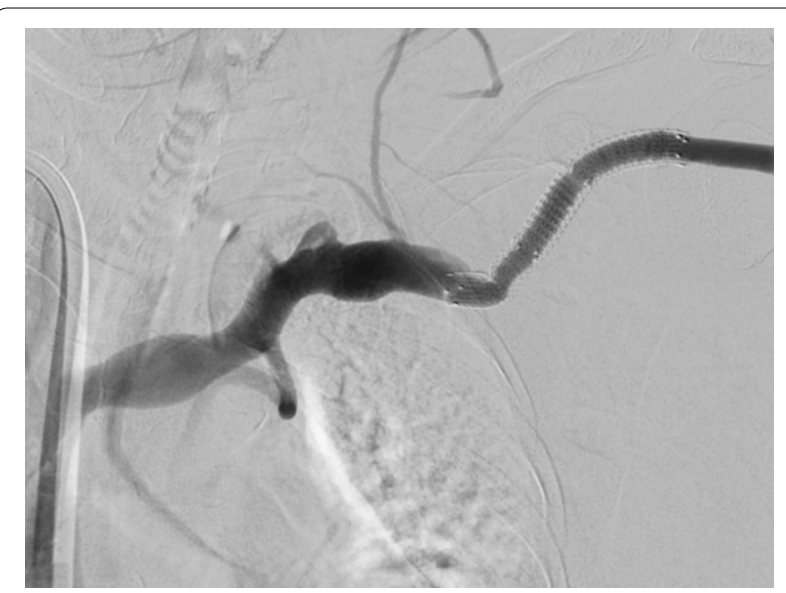

Fig. 2 Follow-up fistulogram shows intact cephalic arch with nonsignificant narrowing distally. Previously seen extravasation and clots are no longer seen 
treated with balloon angioplasty, then we advocate to postpone dialysis via the fistula for 1-2 sessions to facilitate endothelial healing, repeat venogram to reassess the previous site of extravasation. If there is concern for incomplete healing then interventionist has the choice either to angioplasty, stent, or abandon the access if it is not salvageable while maintaining dialysis via another access like temporary or tunneled dialysis access.

\section{Conclusions}

Primary management of cephalic arch rupture is a prolonged-low pressure balloon angioplasty, with covered stent across the site of extravasation if persisted. This case depicted a delayed vascular rupture following hemodialysis in patient with previously controlled extravasation that necessities covered stent placement. No data in the literature suggested the time required to avoid dialysis and improve healing.

\section{Abbreviation}

ESRD: End-stage renal disease.

\section{Acknowledgements}

None.

\section{Authors' contributions}

AA-Gathering data, performing the procedure, writing the manuscript. All authors have read and approved the manuscript.

\section{Funding}

None.

\section{Declarations}

Ethics approval and consent to participant

Not Applicable.

\section{Consent for publication}

Written informed consent was obtained from study participant and available upon request.

\section{Availability of data and materials}

Not applicable.

\section{Competing interests}

None.
Received: 2 June 2021 Accepted: 8 August 2021

Published online: 11 August 2021

\section{References}

1. Vascular Access 2006 Work Group (2006) Clinical practice guidelines for vascular access. Am J Kidney Dis Off J Natl Kidney Found 48(1):176-247. https://doi.org/10.1053/j.ajkd.2006.04.029

2. Hammes M, Funaki B, Coe FL (2008) Cephalic arch stenosis in patients with fistula access for hemodialysis: relationship to diabetes and thrombosis. Hemodial Int Int Symp Home Hemodial 12(1):85-89. https://doi. org/10.1111/j.1542-4758.2008.00246.x

3. McLennan $\mathrm{G}$ (2016) Stent and stent-graft use in arteriovenous dialysis access. Semin Intervent Radiol 33(1):10-14. https://doi.org/10.1055/s0036-1571806

4. Rajan DK, Clark TW, Patel NK, Stavropoulos SW, Simons ME (2003) Prevalence and treatment of cephalic arch stenosis in dysfunctional autogenous hemodialysis fistulas. J Vasc Intervent Radiol 14(5):567-573. https://doi.org/10.1097/01.rvi.0000071090.76348.bc

5. Dale JD, Dolmatch BL, Duch JM, Winder R, Davidson IJ (2010) Expanded polytetrafluoroethylene-covered stent treatment of angioplasty-related extravasation during hemodialysis access intervention: technical and 180-day patency. J Vasc Intervent Radiol 21(3):322-326. https://doi.org/ 10.1016/j.jvir.2009.10.042

6. Turmel-Rodrigues L, Pengloan J, Baudin S, Testou D, Abaza M, Dahdah G, Mouton A, Blanchard D (2000) Treatment of stenosis and thrombosis in haemodialysis fistulas and grafts by interventional radiology. Nephrol Dial Transpl Off Publ Eur Dial Transpl Assoc Eur Renal Assoc 15(12):2029-2036. https://doi.org/10.1093/ndt/15.12.2029

7. Pappas JN, Vesely TM (2002) Vascular rupture during angioplasty of hemodialysis raft-related stenoses. J Vasc Access 3(3):120-126. https://doi. org/10.1177/112972980200300307

8. Weng MJ, Chen MC, Liang HL, Pan HB (2013) Treatment of hemodialysis vascular access rupture irresponsive to prolonged balloon tamponade: retrospective evaluation of the effectiveness of $\mathrm{N}$-butyl cyanoacrylate seal-off technique. Korean J Radiol 14(1):70-80. https://doi.org/10.3348/ kjr.2013.14.1.70

9. Rundback JH, Leonardo RF, Poplausky MR, Rozenblit G (1998) Venous rupture complicating hemodialysis access angioplasty: percutaneous treatment and outcomes in seven patients. AJR Am J Roentgenol 171(4):1081-1084. https://doi.org/10.2214/ajr.171.4.9763001

10. Kim DH, Goo DE, Yang SB, Moon C, Choi DL (2005) Endovascular management of immediate procedure-related complications of failed hemodialysis access recanalization. Korean J Radiol 6(3):185-195. https://doi.org/10. 3348/kjr.2005.6.3.185

11. Quencer KB, Kinney T (2017) Angioplasty-induced cephalic arch rupture. J Clin Interv Radiol ISVIR 1:196-198. https://doi.org/10.1055/s-0037-16070 34

\section{Publisher's Note}

Springer Nature remains neutral with regard to jurisdictional claims in published maps and institutional affiliations. 